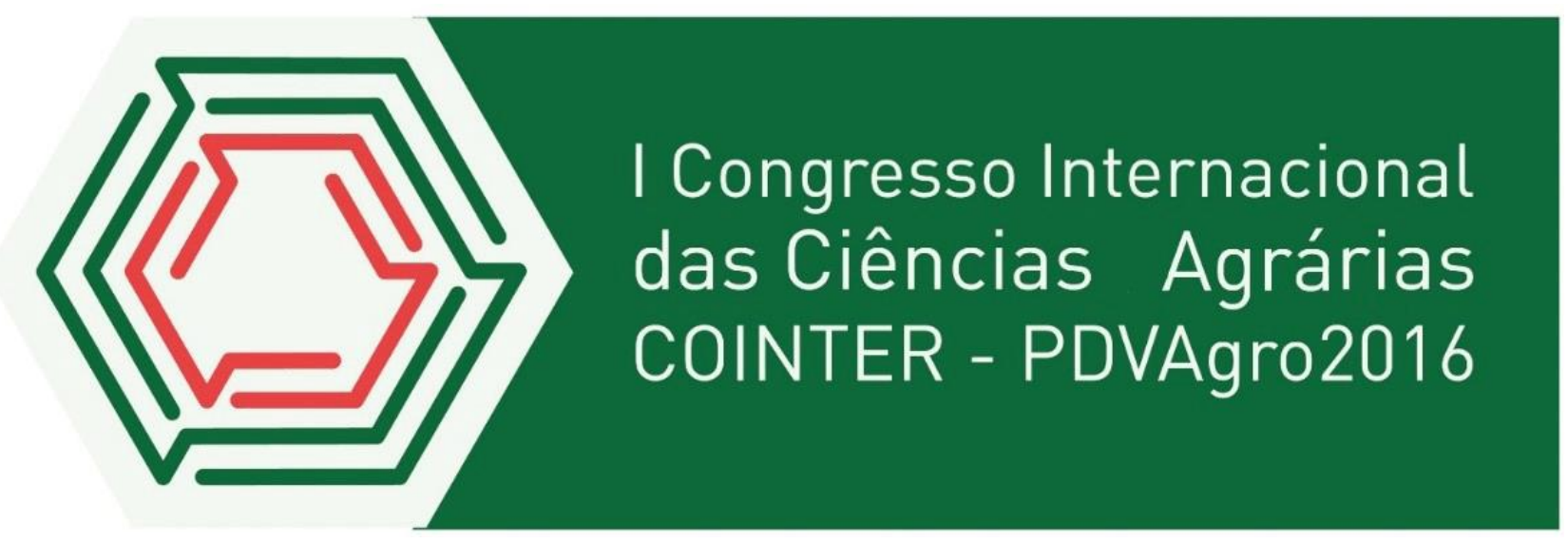

\title{
EFEITOS DA COBERTURA MORTA RESIDUÁRIA SOBRE O DESEMPENHO DE MUDAS DE TAMARINDO
}

\author{
Apresentação: Comunicação Oral
}

Sebastiana Joelma de Azevedo Santos ${ }^{1}$; José Wellington de Medeiros Estrela ${ }^{2}$; Frederico Campos Pereira $^{3}$

\begin{abstract}
Resumo
A utilização de cobertura morta ainda não é uma prática tradicional realizada pelos agricultores da região nordestina, mas acredita- se que essa técnica possa ser vantajosa para áreas em função das condições de solo exigidas para o cultivo desta espécie, restando apenas analisar sua economicidade. A utilização de resíduos orgânicos oriundos de marcenaria como cobertura morta é uma alternativa promissora viável na produção de mudas e no cultivo de plantas, reduzindo os custos e o acúmulo desses materiais no ambiente. O objetivo deste trabalho foi avaliar os efeitos da cobertura morta sobre o desempenho de mudas de tamarindo (Tamarindus indica). O delineamento experimental foi o inteiramente casualisado, com dois tratamentos (sem e com cobertura morta) e com nove repetições, conduzido entre os meses de junho a setembro de 2015. As mudas de tamarindeiro foram produzidas em tubetes cônicos contendo substrato com e sem o uso de cobertura morta. Observou-se que $80 \%$ das plântulas de tamarindo germinaram após o $8^{\circ}$ dia da semeadura, com taxa de sobrevivência de $65 \%$. As que não receberam cobertura teve um menor número de germinação com $30 \%$ a sua taxa de sobrevivência. Após três meses foram avaliadas as variáveis altura da parte aérea, número de folhas e diâmetro caulinar. A adição da cobertura morta não influenciou no parâmetro físiológico número de folhas. As variáveis altura e diâmetro caulinar foram influenciados pelo uso da cobertura. Resíduos vegetais oriundos de marcenaria podem ser utilizados como cobertura do solo favorecendo a umidade e a quantidade de matéria orgânica, além da redução da demanda hídrica, sendo facilmente adquirido pelo agricultor.
\end{abstract}

Palavras-Chave: Cobertura vegetal, resíduos orgânicos, sustentabilidade, Tamarindus indica.

\section{Introdução}

O tamarindo (Tamarindus indica) é uma fruta originária da África equatorial e da Índia. O tamarindeiro é uma árvore com uma copa densa e pode alcançar até $25 \mathrm{~m}$, sendo apreciada também como forma de ornamentação em áreas urbanas. Possui altor teor de proteínas, gliricídios e elementos

\footnotetext{
${ }^{1}$ Pós-graduação em Gestão dos recursos ambientais do semiárido, IFPB/ Campus Picuí, joelmaifpbpicuiy@gmail.com

${ }^{2}$ Graduação em Agroecologia, IFPB/ Campus Picuí, wellingtonestrela18@hotmail.com

${ }^{3}$ Professor de Agroecologia, IFPB/ Campus Picuí, fredcampos2000@yahoo.com.br
} 
minerais sendo utilizado na fabricação de refrescos, sorvetes, polpas, etc., além de servir como ingrediente de temperos para alimentos. Suas sementes também são usadas como estabilizantes de sucos, outros alimentos industrializados e cola de tecidos (VASCONCELOS; MENEZES, 2003). No Brasil, a fruta é muito consumida nas regiões Norte e Nordeste, tendo se adaptado facilmente, devido ao clima que é mais quente. Seu cultivo merece destaque para essas regiões, bem como tecnologias que mantenha a umidade do solo, a exemplo da cobertura morta.

Cresce em diferentes tipos de solos, pobres e rochosos, possuindo certa tolerância a solos salinos e áreas degradadas, prosperando melhor em solos argilosos, profundos, bem drenados, o que favorece o desenvolvimento do sistema radicular. A árvore não tolera encharcamento e prefere solos mais arejados. O pH ótimo para o tamarindeiro é 5,5 - 6,8 embora também cresça bem em solos alcalinos (GEBAUER et al., 2001). A planta necessita de uma precipitação media anual de 500 -1500 $\mathrm{mm}$ bem distribuídos, uma exigência mínima de $250 \mathrm{~mm}$ e máxima de até $4000 \mathrm{~mm}$, desde que o solo seja bem drenado, suportando uma amplitude térmica de 9,5 - 37 C (GÓES et al., 2009).

A utilização de cobertura ainda não é uma prática tradicional realizada pelos agricultores da região nordestina, mas essa técnica é vantajosa para áreas em função das condições de solo exigidas para o cultivo desta espécie, restando apenas analisar sua economicidade. Em sistemas de cultivo orgânico seu uso é bastante vantajoso como forma de controle de plantas espontâneas, devido às restrições de uso de produtos químicos neste sistema de cultivo. As vantagens da cobertura morta no cultivo do tamarindo, como também em outras culturas, podem se estender desde a maximização da germinação das sementes até a manutenção das condições adequadas de temperatura e umidade de solo necessárias ao ótimo desenvolvimento das raízes e também a redução da demanda hídrica.

O uso da cobertura morta apresenta relevante importância para as regiões áridas e semiáridas do país, constituída por resíduos vegetais, desempenha importante papel no sucesso dos diversos sistemas agrícolas servindo como camada isolante, protegendo o solo das amplitudes térmicas diurnas, reduzindo a evaporação, mantendo o solo úmido mesmo durante longo período de estiagem, enriquecendo-o em matéria orgânica e proporcionando ambiente favorável ao desenvolvimento das populações de invertebrados (ALVES et al.,1995).

A utilização de resíduos orgânicos oriundos de marcenaria como cobertura morta é uma alternativa viável promissora para a produção de mudas como também o cultivo de plantas frutíferas, reduzindo os custos e o acúmulo desses materiais no ambiente. Contudo, objetivou-se com este trabalho avaliar os efeitos da cobertura morta sobre o desempenho de mudas de tamarindo (Tamarindus indica).

\section{Fundamentação Teórica}




\section{Benefícios da cobertura morta}

A cobertura morta, também chamada de "mulch", é uma técnica que consiste em distribuir sobre a superfície do solo uma camada de palhas ou outros resíduos vegetais entre as linhas das culturas ou apenas até a projeção da copa das plantas. No Nordeste do Brasil, onde ocorre um período chuvoso e outro seco durante o ano, a cobertura morta apresenta uma série de benefícios.

Diversos autores citados por Pereira e Peres (2006) comprovam os benefícios dessa técnica: I) melhora a qualidade dos produtos, como acontece com a produção abóbora e melancia; II) incrementa a produtividade das culturas (PACHECO, 2003); III) prolonga o tempo de disponibilidade de água no solo (BRASIL SOBRINHO et al., 1991); IV) reduz as variações de temperaturas do solo (CERVELLINI; SALATI, 1993); V) aumenta a estabilidade dos agregados do solo (RANZANI et al., 2001); VI) elimina o desenvolvimento das plantas espontâneas; VII) aumenta a fertilidade do solo (MEDCALF, 1995); VIII) reduz ou elimina a possibilidade de erosão (BARUQUI; FERNANDES, 1999), pelo bloqueio do impacto direto da chuva, e proporciona economicidade dos cultivos. A fruticultura nordestina situada na região dos tabuleiros litorâneos é constituída de solos arenosos com sérios problemas de deficiência hídrica e baixa fertilidade natural.

\section{Influência da cobertura morta sobre a temperatura do solo}

A temperatura do solo é um importante fator no crescimento e desenvolvimento vegetal. A importância da temperatura do solo ficou evidenciada nos trabalhos de Hatfield e Egli (1994); Reichardt (2005) e Nielsen et al. (1996).

Wade e Sanchez (1993), estudando o efeito da cobertura morta, verificaram que a temperatura superficial era diminuída em $5^{\circ} \mathrm{C}$, enquanto que a incorporação do resíduo ao solo não afetou a temperatura do solo. Trabalho realizado por Oliveira et al. (2008) determinou que a temperatura do solo é influenciada pela cobertura do solo proporcionada por leguminosas e resíduos vegetais.

Os autores utilizando-se de geotermômetros de solo fixados nas profundidades de $2,0 \mathrm{~cm} ; 5,0$ $\mathrm{cm} ; 10,0 \mathrm{~cm} ; 20,0 \mathrm{~cm}$ e 40,0 cm, obtiveram médias de temperatura de solo a cada duas horas, no Campo Experimental de Pacajus da Embrapa Agroindústria Tropical, em uma área descoberta. Foi verificado que as temperaturas próximas à superfície do solo $(2,0 \mathrm{~cm}$ e 5,0 cm), registradas às 13:00 horas, durante os meses de julho a dezembro, frequentemente excedem a $40^{\circ} \mathrm{C}$.

\section{Metodologia}

A pesquisa é de natureza qualitativa do tipo experimental. O estudo foi conduzido no Instituto Federal de Educação, Ciência e Tecnologia da Paraíba, Campus Picuí. O experimento foi instalado em delineamento inteiramente casualisado, com nove repetições, utilizando tubetes cônicos de 
plástico rígido com substrato sem e com cobertura morta (2 tratamentos), totalizando 108 plantas.

Para a produção das mudas o substrato foi preparado a partir de uma mistura de 3 partes de solo para 1 de esterco bovino. O experimento foi conduzido entre os meses de junho a setembro de 2015.

A cada 15 dias era realizada a reposição da cobertura morta com irrigação diariamente. O material utilizado para a cobertura morta foi coletada em uma marcenaria da cidade de Picuí-PB, oriunda de material residuário proveniente de partículas maiores quando trabalhada a madeira timborana, com auxílio de máquinas.

As variáveis analisadas foram número de folhas, altura $(\mathrm{cm})$ e diâmetro caulinar $(\mathrm{mm})$ após 90 dias da germinação. Após a coleta, os dados foram tabulados, utilizando-se procedimentos de porcentagem e análise descritiva e as figuras foram produzidas com o programa da Microsoft, Excel 2007.

\section{Resultados e Discussão}

Observou-se que $80 \%$ das plântulas de tamarindo emergiram após o $8^{\circ}$ dia da semeadura. Cerca de $65 \%$ sobreviveram. As que não receberam cobertura teve um menor número de germinação com $30 \%$ a sua taxa de sobrevivência.

Aos 90 dias foram realizadas as avaliações biométricas das plantas número de folhas, altura e diâmetro caulinar. Verificou-se que o substrato adicionado a cobertura vegetal para o parâmetro número de folhas não diferiu significativamente com valores médios de 9 folhas para o solo com substrato e 8 para o substrato sem cobertura (Figura 1).

Figura 1. Número de folhas de mudas de Tamarindus indica cultivadas em substrato com e sem cobertura morta. Fonte: Própria.

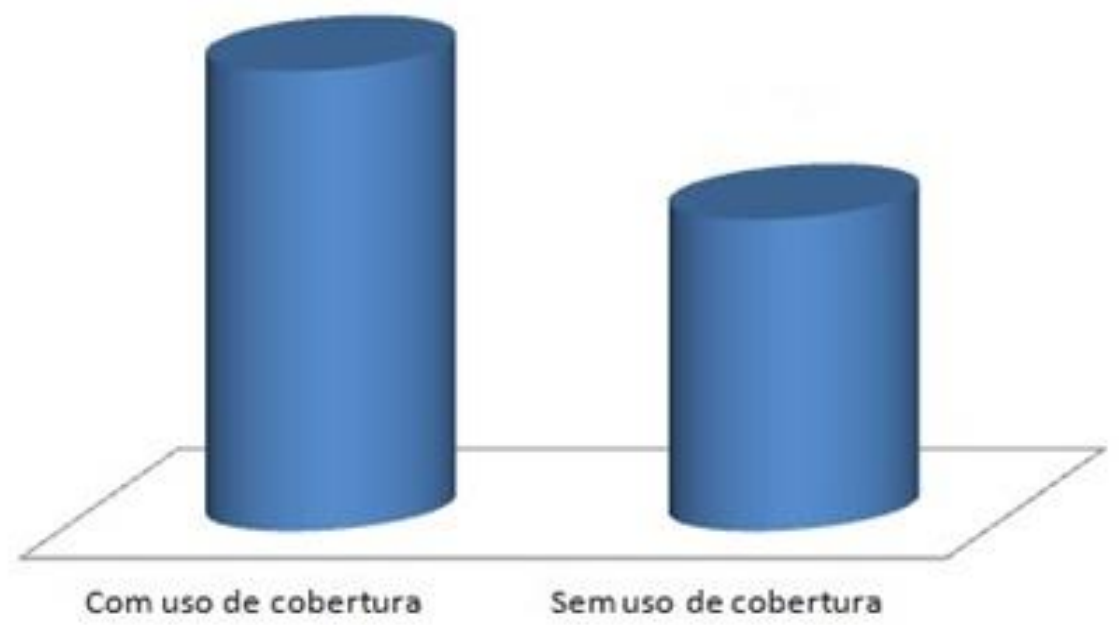


Resultados semelhantes para esse parâmetro foi obtidos em trabalho realizado por Andreola et al, 2000, com mudas de aveia preta e nabo forrageiro cultivados com cobertura vegetal.

A incorporação da cobertura do solo, apesar de muitas vezes ser uma quantidade considerável de massa, parece haver pouca influência sobre a propriedade fisiológica área foliar das plantas. Isso porque essa prática cria condições favoráveis do ambiente à decomposição do material incorporado.

Segundo Chitarra (1994), o desenvolvimento de uma planta pode ser estimado, dentre outros fatores, pela quantidade de tecido foliar que ela produz. Quanto maior a quantidade de área foliar, maior será a superfície fotossintética ativa, e por consequência maior a produção de energia e assimilados. Dessa forma, pode-se entender que uma planta que tenha alta capacidade de acumular tecido foliar poderá apresentar grande vantagem competitiva, principalmente, no momento crítico que representa o seu estabelecimento.

Quanto a variável altura das plantas foi observado um melhor desempenho das mudas de Tamarindus indica nos substratos que receberam cobertura morta. Os valores médios obtidos quando adicionado cobertura morta para a altura foi $15,8 \mathrm{~cm}$ e $9,7 \mathrm{~cm}$ para plântulas com e sem adição de cobertura morta, respectivamente (Figura 2).

Figura 2. Altura de mudas de Tamarindus indica influenciadas pelo uso da cobertura morta. Fonte: Própria.

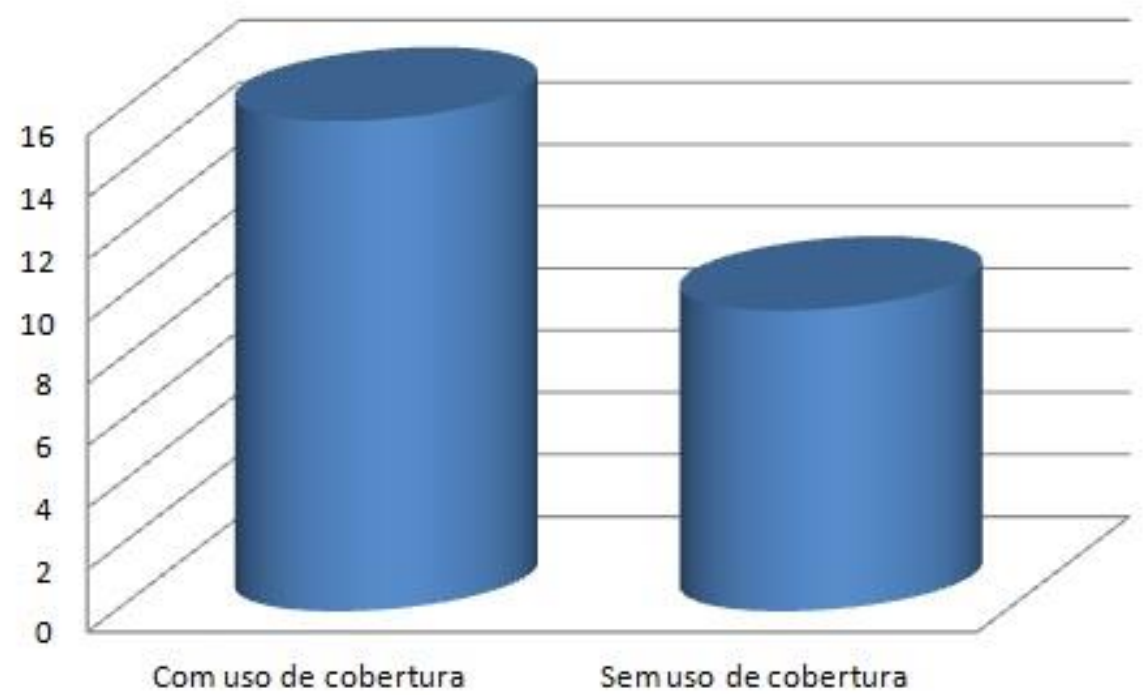

Segundo Resende et al, 2005, em seu trabalho realizado com cenoura (Daucus carota), o uso de cobertura do solo, com serragem e maravalha, se mostrou eficiente no controle de plantas 
espontâneas, bem como a altura das plantas mostraram valores diferenciados em função do material utilizado sem cobertura do solo, nas três épocas em que estas características foram avaliadas.

A cobertura morta do solo protege o mesmo das adversidades do clima. Os materiais mais utilizados são as serragens, palhas, folhas, e materiais sintéticos como o plástico, papéis e metais. Esta prática cultural mantém a umidade do solo, promovendo menores perdas de água (ALVES et al.,1995).

Em Mossoró, trabalhos realizados com cobertura orgânica obtidos a partir da palha de carnaúba triturada proporcionou aumento no desenvolvimento do pimentão conforme Negreiros $e t$ al. (1986) e da alface Maia Neto et al. (1987), além de contribuir na redução de plantas adventícias.

O desenvolvimento inicial das plantas de Tamarindo sem o uso da cobertura foi relativamente menor. Na avaliação do diâmetro caulinar o substrato que recebeu a cobertura atingiu valor médio de 0,4 mm, apresentando também condições favoráveis para o desenvolvimento dessa variável. E apenas $0,2 \mathrm{~mm}$ para o substrato que não foi utilizado a cobertura (Figura 3).

Figura 3. Diâmetro caulinar de mudas de Tamarindus indica influenciadas pelo uso da cobertura morta. Fonte: Própria.

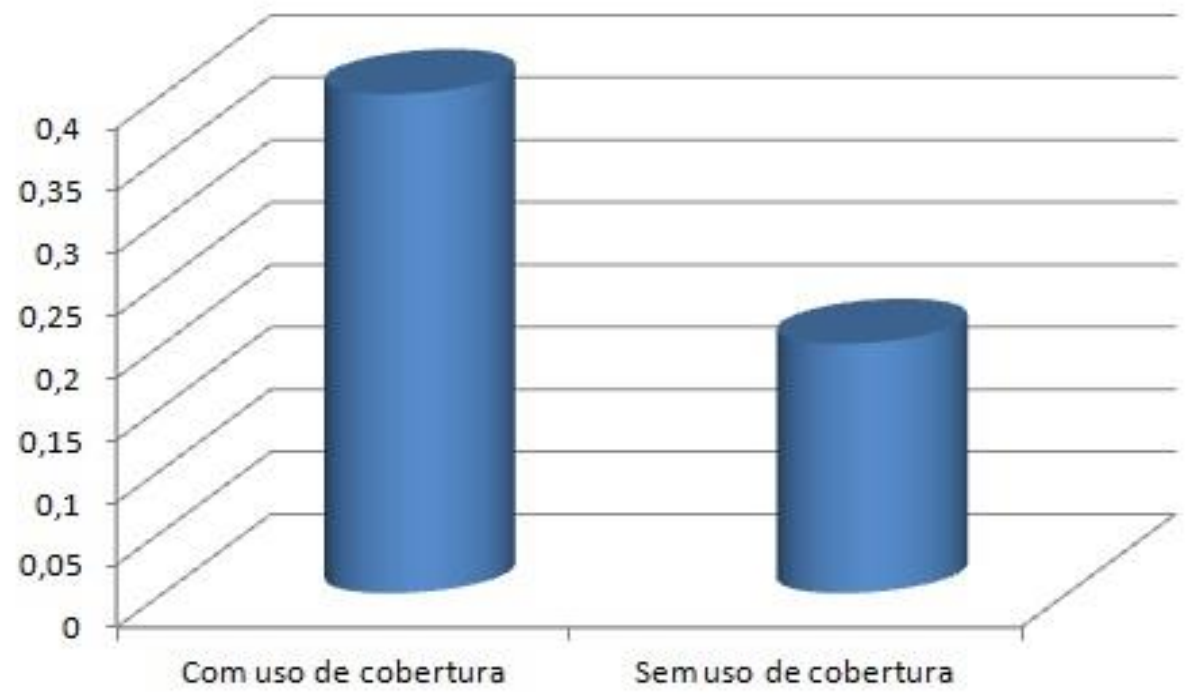

Situação semelhante foi observado também por Miyasaka et al. (2001) em experimentos realizados com taro (Colocasia esculenta) destacando também que o uso de materiais derivados de madeira e restos vegetais como cobertura de solo associados à adubação orgânica, foram eficientes na manutenção da umidade, resultando em maior peso de matéria fresca e seca. 
Bragagnolo e Mielniczuk et al. (1990) afirmam que a cobertura do solo reduz a perda de água por evaporação, além de diminuir as oscilações da temperatura, dependendo da insolação e da umidade do solo. O seu emprego traz vantagens como alteração do regime térmico, conservação da água, redução da perda de nutrientes por lixiviação, além da melhoria das qualidades físicas e químicas do solo (FIALHO et al., 1991). Diante da dificuldade de se encontrar, na literatura, trabalhos realizados com frutíferas e uso de cobertura morta no solo, sugere-se que experimento como este sejam realizados.

\section{Conclusões}

A adição da cobertura morta não influenciou no parâmetro fisiológico número de folhas de plântulas de Tamarindus indica.

As variáveis altura e diâmetro caulinar foram influenciados positivamente pelo uso da cobertura morta.

Resíduos vegetais oriundos de marcenaria podem ser utilizados como cobertura do solo favorecendo a umidade e a quantidade de matéria orgânica, além da redução na demanda hídrica.

\section{Agradecimentos}

Ao IFPB - Instituto Federal de Educação, Ciência e Tecnologia da Paraíba, Campus Picuí.

Ao NEA - Núcleo de Estudos em Agroecologia.

Ao GPES - Grupo Paraibano de Estudos Socioambientais.

\section{Referências}

ALVES, A. G. C.; COGO, N. P.; LEVIEN, R. Relações da erosão do solo com a persistência da cobertura vegetal morta. Revista Brasileira Ciência Solo,19:127-132, 1995.

ANDREOLA, F.; COSTA L. M.; OLSZEVSKI, N. Influência da cobertura vegetal de inverno e da adubação orgânica e, ou, mineral sobre as propriedades físicas de uma terra roxa estruturada. Revista Bras. Ci. Solo, 24:857-865, 2000.

BARUQUI, A. M.; FERNANDES, M. R. Práticas de conservação do solo. Informe Agropecuário, Belo Horizonte, v. 11 , n. 128, p. 55-68, 1999.

BRAGAGNOLO, N.; MIELNICZUK, J. Cobertura do solo por palha de trigo e seu relacionamento com a temperatura e umidade do solo. Revista brasileira de ciência do solo, Viçosa, v. 14, n. 3, p. 369-374, 1990.

BRASIL SOBRINHO, M. O. C.; MELLO, F. A. F.; COURY, T. Efeitos da cobertura morta sobre algumas características de um solo plantado com café. In: CONGRESSO BRASILEIRO DE CIÊNCIA DO SOLO, 7., 1959, Piracicaba, SP. Resumos... Campinas: SBCS, 1991. p. 61. 
CERVELLINI, A.; SALATTI, E. Influência da cobertura morta na temperatura do solo. In: CONGRESSO BRASILEIRO DE CIÊNCIA DO SOLO, 7., 1959, Campinas, SP. Resumos... Campinas: SBCS, 1993. p. 19.

CHITARRA, M. J. F. Colheita e qualidade pós-colheita de frutos: Informe Agropecuário, Belo Horizonte, v.17, n.179. p.8-18. 1994.

FIALHO, J. F.; BORGES, N. F.; BARROS, N. F. Cobertura vegetal e as características químicas e físicas e atividade da microbiótica de um latossolo vermelho-amarelo distrófico. Revista brasileira de ciência do solo, Viçosa, v. 15, n. 1, p. 21-28, 1991.

GEBAUER, J.; EL-SIDDIG, K.; EBERT, G. Response of Tamarindus indica seedlings to salt stress. Journal of Applied Botany, Hamburg, v. 75, n. 3, p. 97-100, 2001.

GÓES, G. B. et al. Crescimento inicial de muda tipo pé-franco de tamarindeiro (Tamarindus indica L.) em diferentes níveis de salinidade na água. Revista Agrarian, Dourados, v. 2, n. 5, p. 63-70, 2009.

HATFIELD, J. L.; EGLI, D. B. Effect of temperature on the rate of soybean hypocotyl elongation and field emergence. Crop Science Madison, v. 14, p. 423-426, 1994.

MAIA NETO, I. M. et al. Efeito da cobertura morta sobre o comportamento da alface na microrregião salineira do RN. Horticultura Brasileira, Brasília, v. 5, n. 1, p. 42, 1987.

MEDCALF, J. C. Estudos preliminares sobre aplicação de cobertura morta em cafeeiros novos no Brasil. New York: IBEC/Research Institute, 1995. 59 p. (Boletim, 12).

MIYASAKA, S. C.; HOLLYER, J. R.; KODANI, L. S. Mulch and compost effects on yield and corm rots of taro. Field Crops Research, Amsterdam, v. 71, n. 2, p. 101-112, 2001.

NEGREIROS, M. Z. et al. Efeito da cobertura morta sobre o comportamento de cultivares de pimentão na microrregião salineira do Rio Grande do Norte. Horticultura Brasileira, Brasília, v. 4, n. 1, p. 44-76,1986.

NIELSEN, G. H.; HOQUE, E. J.; DROUGHT, B. G. The effect of orchard soil management on soil temperature and apple tree nutrition. Canadian Journal of Soil Science, v. 66, n. 4, p. 701-711, 1996.

OLIVEIRA, F. N. S.; LIMA, A. A. C.; COSTA, J. B. A. Adubação verde: alternativa para os solos arenosos do Nordeste. Fortaleza: Embrapa-CNPAT, 2008. 3 p. (Embrapa-CNPAT. Comunicado Técnico, 25).

PACHECO, E. B. Efeito do manejo de um Latossolo Vermelho Amarelo, fase cerrado, sobre o crescimento e produção da laranjeira (Citrus sinensis Osbeck cv. "Baianinha"). Viçosa: UFV, 2003. 52 p. Tese Mestrado.

PEREIRA, J.; PERES, J. R. R. Manejo da matéria orgânica. In: Solos de Cerrados - tecnologias e estratégias de manejo. São Paulo: Nobel/Brasília: Embrapa CPAC, 1986. p. 270-278. 
RANZANI, G.; FREIRE, O. KIEHL, E. J.; CÉSAR, C. M.; SILVA, J. V. C. Influência da cobertura sobre a estrutura do solo. In: CONGRESSO BRASILEIRO DE CIÊNCIAS DO SOLO, 7., Campinas, SP. Resumos... Campinas: SBCS, 2001, p. 16.

REICHARDT, K. Processos de transferência no sistema solo-planta-atmosfera. Campinas: Fundação Cargill, 2005. 466 p.

RESENDE, F. V. et al. Uso de cobertura morta vegetal no controle da umidade e temperatura do solo, na incidência de plantas invasoras e na produção da cenoura em cultivo de verão. Ciênc. agrotec., Lavras, v. 29, n. 1, p. 100-105, jan./fev. 2005.

VASCONCELOS, B. M.; MENEZES, H. C. Caracterização do tamarindo (Tamarindus indica L.) e estudo da extração e estabilidade da polpa. In Congresso Interno de Iniciação Científica da UNICAMP, 2003.

WADE, M. K.; SANCHEZ, P. A. Mulching and green manuring aplications for continuons crop production in the Amazon Basin. Agron. Journal. v. 7, p. 39- 45, 1993. 